\title{
PENCARIAN RUANG WARNA KULIT MANUSIA BERDASARKAN NILAI KARAKTERISTIK $(\lambda)$ MATRIK WINDOW CITRA
}

\author{
Putra Pandu Adikara ${ }^{1}$, Muh, Arif Rahman ${ }^{2}$, Edy Santosa $^{3}$ \\ ${ }^{1,2,3}$ Program Studi Ilmu Komputer, Universitas Brawijaya \\ Email: 19adikara.putra@ub.ac.id, ${ }^{2}$ m_arif@ub.ac.id, ${ }^{3}$ edy144@ub.ac.id
}

(Naskah masuk: 2 Desember 2013, diterima untuk diterbitkan: 17 Februari 2014)

\begin{abstract}
Abstrak
Perkembangan transaksi dan distribusi data yang sangat besar, terutama saat teknologi informasi dan komunikasi melalui web bisa dijangkau oleh siapa saja menggunakan perangkat yang semakin beragam, membuat pengguna memerlukan aplikasi yang serba mudah untuk digunakan. Diantaranya adalah identifikasi obyek yang berada dalam data multimedia berupa teks, gambar maupun suara. Deteksi warna, terutama deteksi warna kulit manusia adalah tahap awal identifikasi keberadaan manusia pada citra 2 dimensi. Terdapat sejumlah metode untuk menentukan apakah suatu pixel pada gambar tersebut merupakan warna kulit manusia. Penelitian sebelumnya telah membuat ruang warna berbasis pixel diantaranya adalah ruang warna RGB, normalisasi RGB, HIS/HSV, TSL, YCbCr dll. Suatu matrik bujur sangkar NxN mempunyai nilai karakteristik $(\lambda)$ sebanyak $N$ dimana nilai masing-masing berupa bilangan real. Suatu citra dapat dipecah menjadi M matrik bujur sangkar dan kemudian dicari nilai $\lambda$ nya. Penelitian ini akan mencari ruang warna kulit manusia berdasarkan nilai karakteristik $(\lambda)$ matrik window citra. Dari hasil pengujian hamper semua warna kulit dapat dideteksi, namun image untuk warna kulit yang tidak mencolok beberapa obyek pada image dapat ditampilkan dengan baik meskipun bukan kulit.
\end{abstract}

Kata kunci: Citra Kulit, Nilai Karakteristik (ג), Matrik Window

\begin{abstract}
The development of the transaction and distribution of huge data, especially when the information technology and communication via the web can be reached by anyone using the increasingly diverse, making the user requires an application that completely easy to use. Among them is the identification of objects that are in the multimedia data such as text, images and sound. Color detection, particularly the detection of human skin color is an early stage identification of human presence on the 2-dimensional image. There are a number of methods to determine whether a pixel in the image is the color of human skin. Previous studies have made such pixel based color space is RGB color space, normalized RGB, HIS/HSV, TSL, YCbCr etc. An NxN square matrix has eigenvalues ( $\lambda$ ) of $N$ where the value of each form of real numbers. An image can be broken down into a square matrix $M$ and then sought its $\lambda$ value. This study will look for human skin color space based on the value of the characteristic $(\lambda)$ matrix image window. From the test results almost all skin colors can be detected, but the image for an inconspicuous color multiple objects in the image can be displayed well although not leather.
\end{abstract}

Keywords: skin image, value of the characteristic(ג), Matrix Windows

\section{PENDAHULUAN}

Aplikasi jaringan sosial social seperti facebook memungkinkan pemakainya untuk menampilkan citra yang dapat dinikmati bersama. Jika citra mempunyai obyek manusia maka ada filtur otomatis yang akan mengidentifikasi wajah pada citra tersebut. Untuk bisa melakukan identifikasi wajah maka perlu dilakukan deteksi keberadaan obyek wajah pada citra. Kulit manusia mempunyai warna yang khusus dan bisa dijabarkan dalam bentuk ruang warna kulit manusia. Secara umum warna kulit manusia dapat dilihat pada wajah, tangan, leher dan kaki.

Penelitian tentang ruang warna kulit manusia didasarkan kebutuhan akan aplikasi untuk identifikasi manusia yang ada pada citra tersebut apakah anak-anak, remaja atau tua, penentuan wajah, identifikasi pelaku kejahatan. Identifikasi konten pornografi pada web, perintah menggunakan gesture, pendeteksian gerak tangan dll. Sejumlah penelitian yang dilakukan telah berhasil membuat ruang warna berbasis pixel baik pada citra maupun video diantaranya adalah ruang warna RGB, RGB, HIS/HSV, TSL, YCbCr dll.

Penelitian yang menggunakan ruang warna diantaranya adalah penentuan sejumlah wajah pada video dilakukan melalui perbaikan algoritma pembentukan ruang warna (T. Kim, 2005), penentuan wajah pada video dilakukan dengan cara melakukan estimasi pergerakan wajah (Roberston, 2006), deteksi wajah dengan cara mereduksi noise pada latar belakang citra utama (Arif, 2011), deteksi tangan dengan memperhatikan hasil warna baik diluar maupun didalam ruangan (Kolsh, 2004), deteksi keberadaan konten pornografi dilakukan dengan perhitungan secara statistic (Zhang, 2004). 
Terdapat sejumlah kesulitan dalam penentuan ruang warna. Pertama, kesamaan antara obyek manusia dengan latar belakangnya, kedua, perbedaan kondisi cahaya ketika citra dan video ketika dilakukan perekaman dan ketiga, karakteristik sensor dari alat perekaman citra dan video. Dari ketiga faktor tersebut masih terdapat juga permasalahan yaitu perbedaan warna kulit bangsa bangsa yang ada di dunia (asia, afrika, eropa) dan perbedaan usia masing-masing obyek manusia (Tey, 2008). Sehingga berdasarkan kesulitan-kesulitan diatas terdapat kesempatan untuk selalu meningkatkan metode deteksi warna kulit manusia.

Citra dengan ukuran A x B dapat dibagi menjadi sejumlah $\mathrm{N}$ matrik bujur sangkar. Jika matrik bujur sangkar tersebut dikalikan dengan vektor $\mathrm{X}$ maka dapat dibentuk persamaan $A x=\lambda \mathrm{x}$ atau $(\lambda I-A) x=0$. Karena $x \neq 0$ maka $(\lambda I-A)=0$ dengan demikian nilai karakteristic $(\lambda)$ dapat dicari (Howard A, 2005)

Pendekatan langsung terhadap pixel untuk mengenali apakah pixel tersebut kulit aatau bukan telah banyak dilakukan. Pendekatan tersebut menggunakan ruang warna RGB, YCbCR dll. Namun pendekatann berbasi feature yaitu menggunakan karakteristik box belum banyak dilakukan. Untuk itu ingin dicari ingin dicari adalah bagaimana membangun ruang warna kulit manusia berdasarkan nilai karakteristik $(\chi)$ matrik window citra.

\section{LANDASAN TEORI}

\subsection{Citra Digital}

Citra digital merupakan sebagai fungsi 2 variabel yaitu $\mathrm{f}(\mathrm{x}, \mathrm{y})$. $\mathrm{x}$ dan $\mathrm{y}$ merupakan koordinat spasial sedangkan nilai $\mathrm{f}(\mathrm{x}, \mathrm{y})$ menyatakan intensitas cahaya pada koordinat tersebut. Dalam ruang diskrit maka nilai $x$, y dan $f(x, y)$ menjadi terbatas. Nilai $x$ menyatakan banyaknya pixel perbaris, nilai $y$ menyatakan banyaknya pixel per kolom. Jumlah pixel keseluruhan adalah perkalian nilai $\mathrm{x}$ dan $\mathrm{y}$. Nilai $\mathrm{f}(\mathrm{x}, \mathrm{y})$ antara 0 sampai dengan 255. Nilai tersebut menyatakan derajat keabuan suatu warna (Gonzales, 2006). Nilai 0 menyatakan bahwa pixel tersebut sangat gelap (hitam) sedangkan nilai 255 menyatakan warna pixel tersebut sangat terang (putih).

Citra digital direpresentasikan dalam bentuk array. Setiap nilai intensitas pada elemen array menyatakan posisi nilai pixel tersebut pada array. Gambar 1. Memperlihatkan nilai pixel pada elemen $[\mathrm{I}, \mathrm{j}]$.

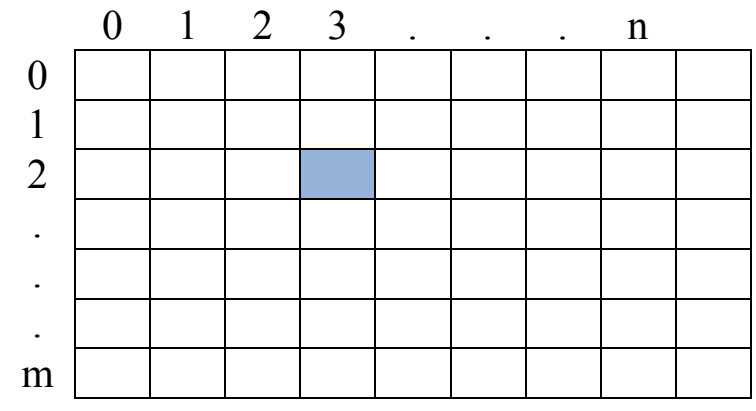

Gambar 2.1. Pixel pada elemen [3,2]

\subsection{Warna RGB}

Setiap pixel mempunyai 3 warna yang dikenal dengan warna RGB yaitu Red, Green dan Blue (Merah, hijau dan biru). Perhatikan gambar 2 berikut:

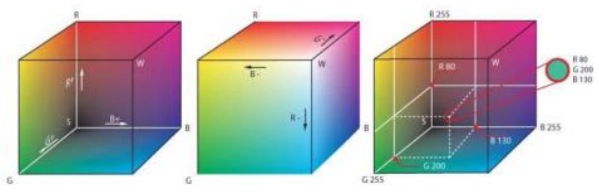

Gambar 2.2. Ruang warna RGB

Warna RGB digunakan untuk membedakan pixel berwarna kulit atau bukan warna kulit manusia menggunakan model warna histogram (Jones, 1999).

\subsection{Normalisasi RGB (NRGB)}

Normalisasi RGB merupakan ekstensi dari warna RGB dimana setiap warna pixel di proporsikan dengan jumlahan keseluruhan warna RGB pada setiap pixel (Y. Ming, 1998). Hal ini untuk mengatasi perbedaan intensitas pada obyek yang sama yang diambil gambarnya pada pencahayaan yang berbeda. Rumusan NRGB dinyatakan sbb:

$$
\begin{aligned}
& =\frac{R}{(R+G+B\}} \\
g & =\frac{G}{R+G+B} \\
b & =\frac{B}{R+G+B}
\end{aligned}
$$

Komponen r, g dan b merupakan elemen nomalisasi dari R, G dab B. Hasil dari normalisasi menyebabkan perbedaan iluminasi tiap pixel menjadi tidak tergantung pada pencahayaan pada saat pengambilan citra karena adanya penjumlahan $\mathrm{r}+\mathrm{g}+\mathrm{b}=1$. Rumusan diatas cukup dicari 2 elemen saja karena 1 elemen lainnya bisa dibentuk dari rumusan $\mathrm{r}+\mathrm{g}+\mathrm{b}=1$. 


\subsection{Warna HSV}

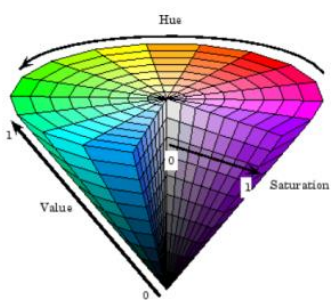

Gambar 2.3. Model Warna HSV

HSV adalah singkatan dari Hue, Saturation dan Value. HSV adalah pandangan perspektif warna yang mendekati warna yang dapat dilihat oleh mata manusia (Y. Ming, 1998). Gambar 3 adalah model warna HSV.

Nilau Hue merupakan sudut putar yang bernilai 0 s/d 360o sedangkan nilai saturasi dan intensitas bernilai $0 \mathrm{~s} / \mathrm{d} 1$. Berikut ini adalah rumusan konversi RGB ke HSV.

Warna $r, g, b$ r,g,b $\in[0,1]$ adalah komponen warna merah, hijau dan biru dari RGB. M adalah $\max (r, g, b)$ dan $\mathrm{m}=\min (\mathrm{r}, \mathrm{g}, \mathrm{b})$ maka

$$
\begin{aligned}
& H_{o}=\left\{\begin{array}{lll}
0 & \text { if } & M=m \\
\left(\frac{6+g-b}{6 \cdot(M-m)}\right) \bmod 1 & \text { if } & M=r \\
\frac{2+b-r}{6 \cdot(M-m)} & \text { if } & M=g \\
\frac{4+r-g}{6 \cdot(M-m)} & \text { if } & M=b
\end{array}\right. \\
& S_{o}=\left\{\begin{array}{lll}
0 & \text { if } & M=m \\
\frac{M-m}{M+m} & \text { if } & M \leq 1-m \\
\frac{M-m}{2-(M+m)} & \text { if } & M>1-m
\end{array}\right. \\
& V_{o}=M
\end{aligned}
$$

\subsection{Warna YCBCR}

$\mathrm{YCrCb}$ dapat dihitung dari nilai warna $\mathrm{RGB}$. Warna $\mathrm{YCrCb}$ digunakan studio televise eropa dan kompresi citra. Y adalah komponen luma, $\mathrm{Cr}$ adalah warna merah dan $b$ adalah warna biru chromatic.

$$
\begin{aligned}
Y & =0.299 R+0.587 G+0.115 B \\
C_{r} & =R-Y \\
C_{b} & =B-Y
\end{aligned}
$$

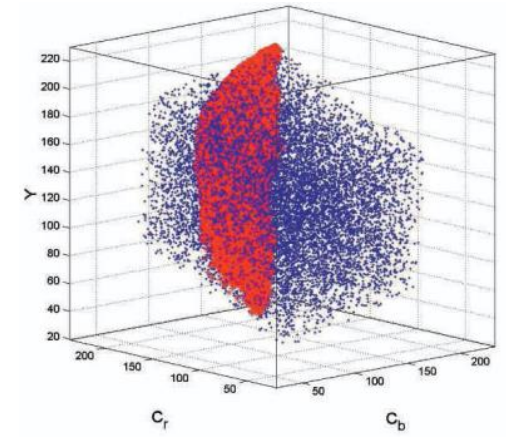

Gambar 2.4. Model Warna $\mathrm{YCrCb}$

\subsection{Model Warna Kulit Wajah}

Model warna kulit wajah didefinisikan Yanjiang \& Baozong (Yanjiang, 2001) setelah melakukan serangkaian uji coba pada citra wajah. Adapun rumusannya adalah sbb:

$0.36 \leqslant r \leqslant 0.465, \quad 0.28 \leqslant g \leqslant 0.363$,

$0 \leqslant H \leqslant 50, \quad 0.20 \leqslant S \leqslant 0.68, \quad 0.35 \leqslant V \leqslant 1.0$,

Model warna lainnya juga dikembangkan dengan rumusan sbb: (Kovach P, 2003). Nilai pixel (R, G, B) diklasifikan sebagai warna kulit manusia jika

$R>95$ and $G>40$ and $B>20$ and

$\operatorname{Max}\{R, G, B\}-\min \{R, G, B\}>15$ and (11)

$|R-G|>15$ and $R>G$ and $R>B$

\subsection{Nilai Eigen Dan Vektor Eigen}

Vektor eigen $\mathrm{x}$ dari matrik bujur sangkar A adalah vektor tidak nol yang dikalikan dengan matrik A. Untuk setiap vector eigen terdapat nilai eigen yang merupakan faktor penskala ketika dikalikan dengan matrik A. Rumusnya adalah sbb:

$$
\begin{aligned}
A x & =\lambda x \\
(\lambda I-A) x & =0
\end{aligned}
$$

Karena vector eigen $\mathrm{x}$ tidak sama dengan nol maka nilai eigen dicari dengan rumus sbb:

$$
\operatorname{det}(\lambda I-A)=0
$$

\subsection{Principal Componen Analysys}

PCA adalah metode yang popular digunakan untuk mengurangi dimensi dari representasi data yang biasanya dapat dinyatakan dalam bentuk vector. Berkurangnya dimensi tersebut mengakibatkan jumlah komputasi berkurang dan 
jumlah kebutuhan memori juga berkurang. Adapun algoritmanya sbb:

1. Bentuk data menjadi $\mathrm{x}_{\mathrm{I}}=\left(\mathrm{x}_{1}, \mathrm{x}_{2} \ldots \mathrm{x}_{\mathrm{N}}\right)$ dimana $\mathrm{x}_{\mathrm{i}}$ adalah vector kolom $(\mathrm{mx} 1)$

2. Hitung mean (rata-rata) nya $u=\frac{1}{N} \sum_{n-1}^{N} X[m, n]$

3. Hitung deviasi dari rata-rata $B=X-u$

4. Hitung matrik covariance $\mathrm{C}=\frac{1}{n} \sum B \cdot B^{*}$

5. Hitung eigen vector dan eigen value dari matrik C

Eigen value $->D[p, q]=\lambda_{m} \quad$ untuk $m=$ $p=q$ Dan

$$
D[p, q]=0 \text { untuk } p \neq q
$$

Eigen vector $\mathrm{V}_{\mathrm{i}}$ untuk $\mathrm{i}=1$..n

6. Atur kembali eigen value dan ambil yang besar (hilangkan eigen value yang mempunyai nilai mendekati nol).

7. Dimensi dari eigen vector $\mathrm{Vi}=1 . . \mathrm{r}$ dimana $\mathrm{r}<\mathrm{n}$.

\section{PERANCANGAN SISTEM}

\section{Data Uji}

Data uji berupa image yang mempunyai warna latar belakang yang sama / hampir sama dengan citra wajah. Citra wajah yang memuat banyak wajah sejumlah 6. Data diambil dari beberapa sumber (internet dan koleksi pribadi). Data uji terdiri atas 50 potongan gambar yang memuat kulit manusia.

\section{Algoritma}

Membaca Data

1. Ubah nilai RGB semua citra menjadi normalized RGB

2. Bagi tiap citra menjadi sejumlah matrik bujur sangkar $\mathrm{SxS}$

3. Untuk setiap matrik bujur sangkar bentuk menjadi vector kolom

4. Hitung rata-rata dari matrik

5. Hitung covariance matrik

6. Cari nilai eigen dan vector eigen nnya

7. Urutkan nilai eigen dan lakukan pengurutan dari besar ke kecil. Nilai eigen yang benilai kecil dapat diabaikan (dihilamgkan)
8. Terbentuk vector eigen dengan dimensi yang lebih kecil

Mendeteksi Obyek

1. Baca image yang mengandung wajah dan kulit manusia

2. Buat blok SxS pada citra tersebut

3. Untuk tiap blok $\mathrm{SxS}$, bentuk menjadi vector kolom dengan dimensi $\mathrm{s}^{2} \mathrm{x} 1$

4. Kurangkan dengan rata-rata vector uji

5. Kalikan dengan matrik hasil reduksi dimensi

6. Telusuri hasil

\section{Data Training}

Data uji sebanyak 50 buah yang mempunyai warna kulit. Diantaranya adalah sbb:

Tabel 4.1 : daftar table uji warna kulit

\begin{tabular}{ll}
\hline $\begin{array}{l}\text { Nama } \\
\text { data }\end{array}$ & Gambar \\
\hline 001.jpg & \\
002.jpg & \\
.. & \\
050.jpg & \\
\hline
\end{tabular}

\section{HASIL UJI COBA DAN ANALISA}

Adapun hasil pengujian adalah sebagai berikut:

Tabel 4.4 : hasil pengujian pada data dengan warna kulit yang mencolok

\begin{tabular}{|c|c|c|}
\hline Gambar & Treshold 0.1 & Treshold 0.5 \\
\hline U001.jpg & & \\
\hline U002.jpg & & \\
\hline U003.jpg & & \\
\hline
\end{tabular}

Pengujian pada data dengan warna kulit yang mencolok mampu mendeteksi keberadaan warna kulit hamper semuanya. Namun terdapat deteksi sejumlah obyek yang dianggap kulit. 
Tabel 4.5 : hasil pengujian pada data dengan warna kulit yang tidak mencolok

\begin{tabular}{|c|c|c|}
\hline Gambar & Treshold 0.1 & Treshold 0.5 \\
\hline U001.jpg & $y$ & \\
\hline U002.jpg & & \\
\hline U003.jpg & & \\
\hline
\end{tabular}

Pengujian pada data dengan warna kulit yang tidak mencolok secara umum warna kulit masih bisa dideteksi, namun bercampur dengan obyek lain yang bukan kulit.

\section{KESIMPULAN DAN SARAN}

Secara umum hasil yang diperlihatkan dari pengujian belum memberikan kinerja yang bagus karena adanya obyek-obyek lain yang dianggap sebagai warna kulit. Namun hamper semua warna kulit mampu dideteksi baik pada gambar dengan warna kulit yang mencolok maupun yang bukan mencolok.

Pengembangan lebih lanjut dari penelitian ini bida dilakukan dengan klasifikasi feature berbasis fuzzy untuk memilih manakah yang berwarna kulit maupun bukan kulit

\section{DAFTAR PUSTAKA}

GONZALEZ R \& WOODS. 2002. Digital Image Processing, 2/Ed, Addison-Wesley Longman Publishing Co., Inc.

HOWARD ANTON, CHRIS ROREES. 2005. Elementary Linear Algebra 9ed, Jhon Wiley \& Son.
JONES and J. R. REHG. 1999. Statistical Color Models with Application to Skin Detection. CVPR99.

KOVAC, P. PEER and F. SOLINA . 2003. Human Skin Color Clustering for Face Detection. EUROCON2003.

K“OLSCH and M. TURK. 2004. Robust Hand Detection. Department of Computer Science, University of California, Santa Barbara, CA 93106.

MUH. ARIF RAHMAN, SOLIMUN, NITA DEWI. 2011. Reduksi Latar Belakang Pada Citra Banyak Wajah Untuk Deteksi Wajah, DPP/SPP FMIPA Universitas Brawijaya.

MUH. ARIF RAHMAN. 2011. Face Detection Image Based Rgb Color Using Cube Form, Proceding ICBS.

N. ROBERTSON, I. REID and M. BRADY. 2006. Behaviour Recognition and Explanation for Video Surveillance. University of Oxford, Dept. Engineering Science.

T. KIM, S. LEE, J. LEE, S. KEE and S. KIM. 2005. Integrated Approach of Multiple Face Detection for Video Surveillance Human. Computer Interaction Lab, Samsung AIT, KOREA.

TEY YI CHIN, Fuzzy Skin Detection. 2008. Project Report Faculty Of Computer Science \& Information System University Teknologi Malaysia.

Y. MING-HSUAN, A. NARENDRA. 1998."Detecting Human Faces in Color Images," Proceedings of the International Conference on Image Processing, vol. 1, Oct. 4-7, pp. 127-130

YANJIANG WANG, BAOZONG YUAN. 2001. A novel approach for human face detection from color images under complex background, The Journal Of The Pattern Recognition Society.

ZHENG, M. DAOUDI_and B. JEDYNAK. 2004. Blocking Adult Images Based on Statistical Skin Detection. Electronic Letters on Computer Vision and Image Analysis 4(2):1-14. 